\title{
Lokalitas Konten dalam Visual Kaos Cak-Cuk Surabaya
}

\author{
Arjuna Bangsawan
}

Staff Pengajar Program Studi Desain Komunikasi Visual, Fakultas Seni, Institut Informatika Indonesia (IKADO) Surabaya

Email : arjuna@iii.ac.id

Abstract - In the realm of fashion, t-shirt has a basic function in man dressed as a complement. As it grows a shift in the value of the function t-shirts. In addition to functioning as a complement to dress, $t$ shirts can be used as a medium of communication, conveys criticism, existence, identity portrayal, as well as a means of identity and promotion. Kaos Cak Cuk Surabaya is one of the local T-shirt original regional Surabaya Suroboyoan consistent use in displaying visual culture. Through the language of visual pun and parody are blasted with locality Surabaya, Surabaya Cak Cuk in her locality brings humor and antics.

Keyword :locality, Cak Cuk Surabayavisualshirts, plesetan, parody

\section{PENDAHULUAN}

Dalam fashion, sejarah kaos (t-shirt) belumlah terlalu panjang.Kemungkinan besar kaos baru muncul antara akhir abad ke-19 hingga awal abad ke-20.Kaos berbahan katun biasanya dipakai oleh tentara Eropa sebagai pakaian dalam (di balik seragam), yang fleksibel dan bisa dipakai sebagai pakaian luar jika mereka beristirahat di udara siang yang panas. Istilah "T-Shirt" (metafor yang mungkin diambil berdasar bentuknya) baru muncul di Merriam-Webster's Dictionary pada 1920, dan baru pada Perang Dunia II ia menjadi perlengkapan standar dalam pakaian militer di Eropa dan Amerika Serikat (Kunci Cultural Studies Center, melalui http://kunci.or.id/).

Rebel Without a Cause besutan Nicholas Ray merupakan salah satu film yang semakin mempopulerkan kaos (t-shirt) bagi kaum muda pada paruh kedua era 1950-an. Adalah seorang James Dean, pemeran utama film yang diproduksi pada tahun 1955 tersebut dengan ciri ikonik berupa kaos, celana blue jeans dan tentunya jaket merah. Jika berjalan mundur beberapa tahun sebelum Rebel Without a Cause, Marlon Brando mengagetkan dunia mode dengan kaosnya dalam film gubahan naskah drama yang berjudul A Streetcar Named Desire di tahun 1951. Dalam poster resmi film arahan sutradara Elia Kazan tersebut Marlon Brando terlihat sangat berkarakter mengenakan kaos polos berwarna putih. Melalui tokoh yang 
dilakoninya, Marlon Brando dan James Dean merupakan garda depan yang menjadikan kaos populer melalui film layar lebar.

Meski sudah mulai mendunia sejak 1950an, konvensi mode dunia tetap saja belum memasukkan kaos ke dalam kategori fashion.Kaos tetap saja dianggap sebagai pakaian dalam yang tidak pantas dikenakan sebagai pakaian luar. Memakai kaos masih juga dianggap sebagai tindakan unfashion. Karena itu ketika musik heavy metal mulai digemari anak muda, mereka sengaja memilih kaos oblong sebagai bentuk penolakan terhadap

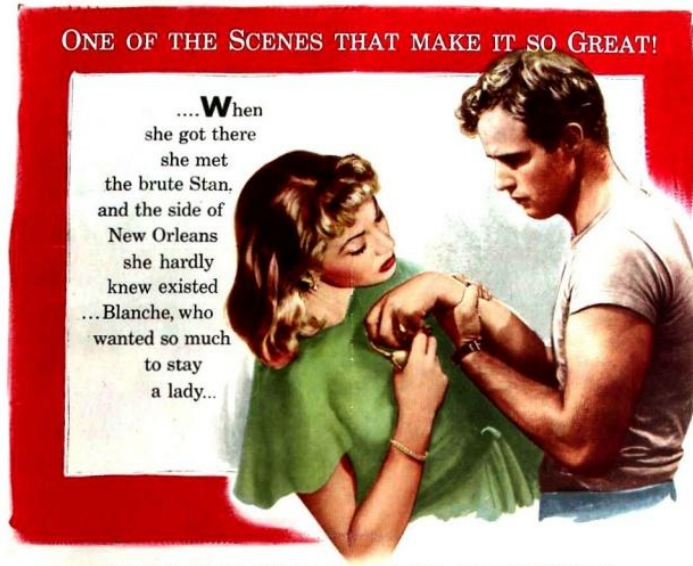

WARNER Bros. BRING the SCREEN ALL THE FIRE OF

\section{"A Streetcar} Named Desire...

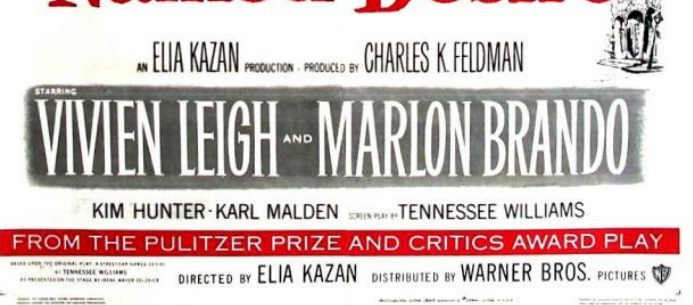

Gambar.1. Poster Film A Street Name Desire

konvensi arus utama mode dunia (high fashion) (McRobbie, 1999). Di Indonesia, kaos dianggap sebagai pakaian santai dan

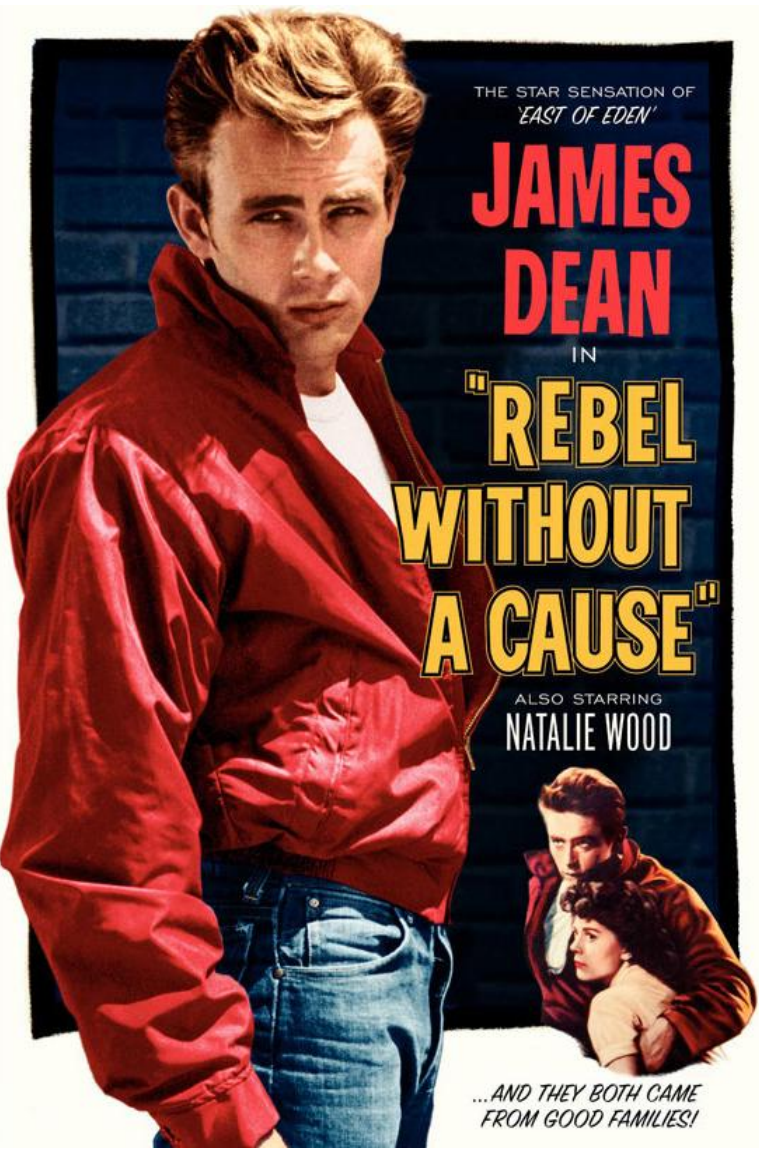

Gambar.2. Poster Film Rebel Without Cause

tidak patut dikenakan pada situasi, waktu dan kondisi formal.

\section{PERGESERAN NILAI KAOS}

Kini seturut perkembangannya, kaos tak pernah lepas dari kultur kaum muda dan mereka yang berjiwa muda. Kaos menjadi penyampai segala bentuk ideologi mulai dari musik, selera, sampai politik. Hal ini merupakan pergeseran nilai budaya karena sebelumnya kaos hanyalah pakaian dalam yang kemudian melalui proses panjang menjadi pakaian luar dan bagian dari budaya pop. Kaos sebagai salah satu jenis pakaian mampu berfungsi sebagai media penyampai pesan.Kaos oblong dipilih karena dipercayai sebagai pengirim pesan 
dengan jangkauan khalayak yang luas, efektif dan bebas.Kaos yang di dalamnya terdapat teks yang menggelitik, nakal, nylekit, seringkali mengundang orang untuk berpikir lebih dalam.

Kaos yang pada awalnya memiliki nilai utama sebagai pakaian telah berevolusi menjadi wahana komunikasi.Kaos membawa pesan dalam sebuah teks terbuka. Bermacam bentuk, gambar, atau kata-kata dalam kaos merupakan pesan akan identitas, pengalaman, perilaku bahkan realitas sosial. Kaos mengkomunikasikan berbagai identitas, diantaranya; penanda lokasi (Yogyakarta, Bali, Bandung), brand (Blackberrry, CocaCola, iphone), institusi (ISI, UGM, ITB, UNESCO). Kaos mengkomunikasikan kelompok atau kolektivitas (Slanker, OI, Kaskus ), tim (Timnas Indonesia, Persib, Persipura), penanda acara, komoditas bernilai, bahkan kepentingan kampanye politik. Selain terdapat nilai - nilai yang ingin dipromosikan atau dikomunikasikan melalui apa yang ditampilkan pemilihan teks ataupun gambar pada kaos merupakan sebuah bentuk dari ekspresi individualistik yang merupakan cara untuk membedakan diri sendiri sebagai individu dan menyatakan beberapa keunikannya.

Kaos sebagai sebuah fashion sesungguhnya berbicara tentang sesuatu yang sangat erat dengan diri kita.Tak heran, kalau dalam kata-kata Thomas Carlyle, pakaian menjadi "perlambang jiwa" (emblems of the soul).Pakaian bisa menunjukkan siapa pemakainya. Sepaham dengan pendapat Umberto Eco, "I speak through my cloth". (Aku berbicara lewat pakaianku).Pakaian yang kita kenakan membuat pernyataan tentang busana
kita.Bahkan jika kita bukan tipe orang yang terlalu peduli soal busana, orang yang bersua dan berinteraksi dengan kita tetap akan menafsirkan penampilan kita seolaholah kita sengaja membuat suatu pesan. Pernyataan ini membawa kita pada fungsi komunikasi dari pakaian yang kita kenakan dalam kehidupan sehari-hari, baik dalam suasana formal maupun informal (Barnard : 2011).

\section{KAOS CAK CUK SURABAYA}

Cak Cuk Surabaya adalah merek yang sudah dipatenkan.Salah satu dari sekian produk kaos lokal di Surabaya.Berbagi pesan dalam karya gambar dan teks Cak Cuk Surabaya menggali dan menyajikan sesuatu yang sangat khas Surabaya. Pemilihan nama Cak Cuk semata memilih kata atau nama yang sangat lekat dan merepresentasikan Surabaya. Cak adalah Mas atau padanan Kakak dalam Bahasa Indonesia, sedangkan Cuk semacam partikel kata yang merupakan forklor jawa timur-an untuk mengungkapkan keakraban yang kerap dipakai dalam percakapan dialek suroboyoan.Cak Cuk Surabaya dari mereknya sekilas tampak nakal. Namun tidak demikian, menurut sang pemilik, "Kami tetap tampil dengan kesan smart yang khas Surabaya." Semua itu dituangkan dalam karya-karya desain , baik berupa gambar maupun kata-kata (Suara Surabaya City Guide: 2012).

Menilik desainnya, kaos Cak Cuk bisa dikelompokkan dalam 5 jenis, diantaranya; (1) berhubungan dengan Surabaya kota pahlawan ; (2)Surabaya kota kuliner; (3) Surabaya kota misuh (umpat); (4) Surabaya 
kota esek-esek; dan (5) Surabaya kota Bonek. Cak Cuk merupakan kaos khas kota/daerah, oleh karena itu konsumen tidak hanya melihat dari segi kualitas saja, akan tetapi faktor region of origin (daerah asal) juga mempengaruhi seorang konsumen untuk memutuskan suatu pembelian. Karena bagi konsumen, memakai produk yang sudah menjadi ikon/ciri khas sebuah kota merupakan kebanggaan tersendiri ketika memakainya.

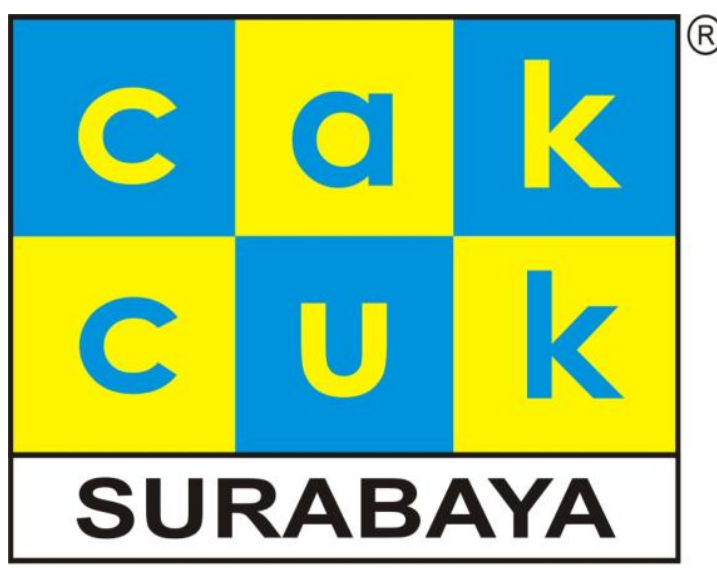

kata kata kota kita

Gambar.3. Cak Cuk Surabaya

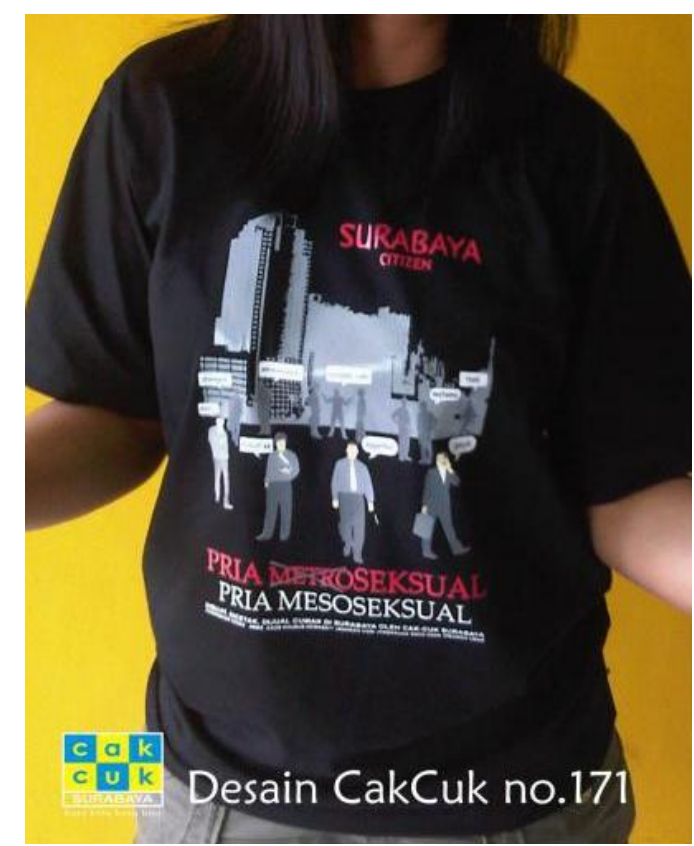

BAHASA PLESETAN KAOS CAK - CUK SURABAYA

Ketika masyarakat Indonesia telah mengalami difusi sosial yang sangat luas akibat pembangunan, modernisasi, dan globalisasi, maka sangat sulit masyarakat Indonesia memiliki kepekaan terhadap permasalahan bangsa dan negaranya sendiri.Inilah yang kemudian mengakibatkan munculnya masalahmasalah sosial.Dalam hal ini yang dimaksud dengan masalah sosial adalah perbedaan antara das sollen (yang seharusnya, yang kita inginkan) dan das sein (yang nyata, yang terjadi).Misalnya saja, ketika sebuah bangsa mengharapkan pemimpin yang sangat sensitif terhadap aspirasi rakyat, ternyata bangsa tersebut menemukan pemimpin yang hanya sensitif terhadap aspirasi golongannya sendiri.Akibatnya timbul perbedaan antara yang ideal dan yang real.

Desain pada kaos Cak Cuk Surabaya sering menggunakan ikon-ikon tempat di Surabaya, tokoh yang mempunyai sejarah bagi kota Surabaya, ataupun fenomenafenomena sosial di kota Surabaya dan sekitarnya. Seringkali desain kaos Cak Cuk Surabaya berisi tentang permasalahan sosial yang terjadi.Sebagai salah satu media untuk menyampaikan aspirasi, Cak Cuk "bermain" dengan bahasa plesetan dan humor. 


\section{INDbONEkSIA indonesta}

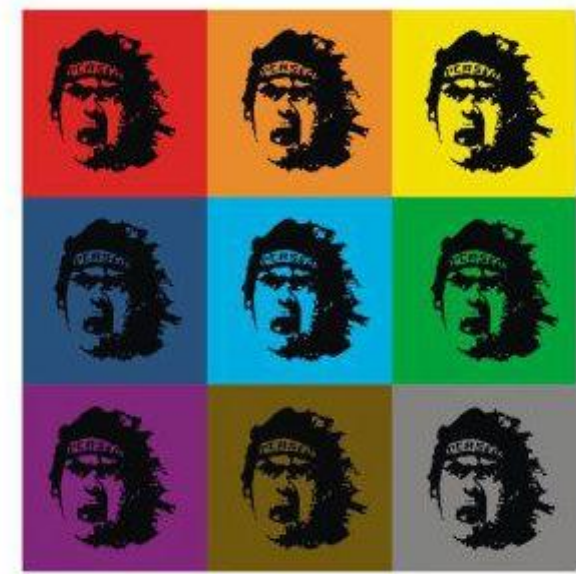

\section{"BONEKKA TUNGGAL IKA" berbeda-beda tetapi tetap bonek juga}

Gambar.5. Kaos Cak Cuk Surabayaplesetan

Menurut kamus Horne plesetan berasal dari akar kata pleset (bahasa Jawa) yang artinya 'meluncur di tempat licin untuk bersenang-senang atau bermain-main dengan kata' sedangkan menurut Kamus Besar Bahasa Indonesia, Bahasa Indonesia menyerap bentuk ini menjadi "peleset": gagal mencapai tujuan, tidak mengenai sasaran, atau terpelanting jatuh (Ariel Heryanto, 1996:110). Bahasa plesetan dianggap penyimpangan dari bahasa yang dipakai masyarakat karena memiliki polapola yang tidak lazim dan tidak sesuai dengan konvensi kebahasaan.Ketidaklaziman memiliki dua kemungkinan anggapan, yakni sebagai hal terpuji atau sebagai hal yang tercela.Plesetan sering dipandang dalam kaitannya dengan hal-hal non-kebahasaan sebagai sifat non-konfrontatif, tidak jujur, tidak serius, dan semaunya. Hal ini terlihat pada sering dipakainya bahasa plesetan

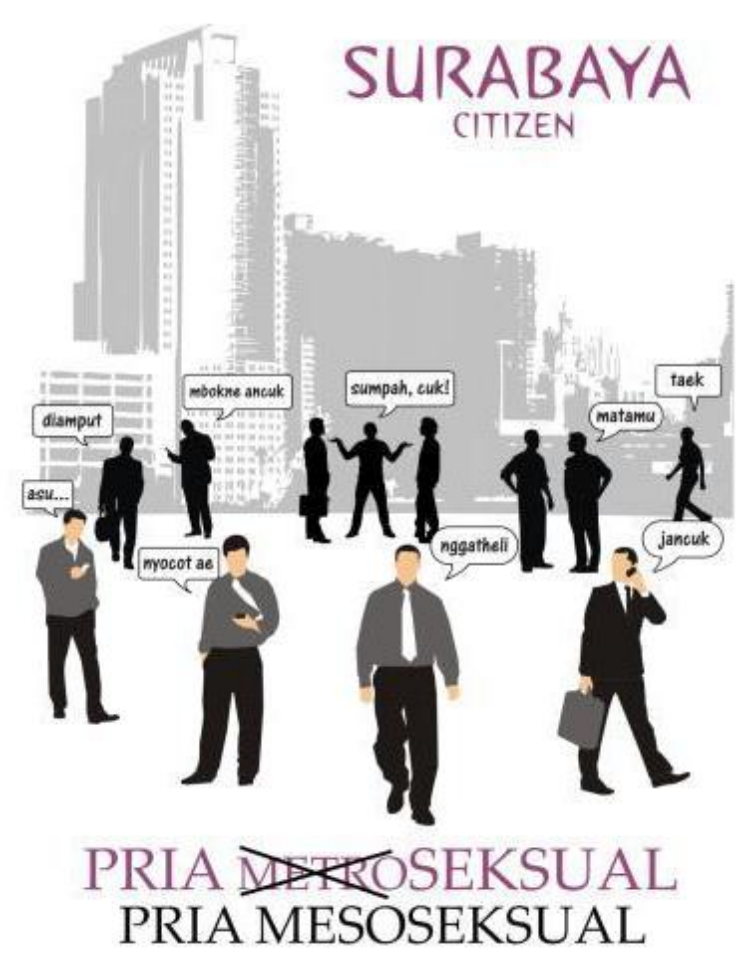

Gambar.6. Kaos Cak Cuk Surabayaplesetan

pada situasi tutur yang banyak menekankan humor dan kelucuan, serta bersifat santai. Pada dasarnya plesetan yang dikenal masyarakat selalu memuat prinsip dan aturan tertentu sebagai unsur pembentuknya. Menurut Ariel Heryanto (1996: 132-133), prinsip plesetan seperti halnya lelucon, hanya akan berhasil apabila ada tiga hal, yaitu (1) kelaziman (acuan yang jelas tentang makna suatu kata dan disepakati bersama); penyelewengan; dan (3) ada pihak yang menerima.

Plesetan tidak sebatas keisengan anak muda yang dianggap masih mencari identitas diri.Bila dikaji lebih dalam bahasa plesetan merupakan salah satu fenomena transisi budaya.Transisi budaya yang dimaksud umumnya mengacu pada perubahan sosial yang melatarbelakangi suatu daerah maupun wilayah untuk memiliki pola bahasa tersendiri. Ariel 
Heryanto membagi bentuk plesetan menjadi tiga kelompok besar sebagai berikut: (1) Plesetan yang hanya "menjegal" suatu rangkaian tanda (penanda dan makna) yang sudah lazim, tanpa diikuti pembentukan suatu susunan pesan baru yang dari sudut kebahasaan tidak terpadu secara formal. Plesetan ini dibagi menjadi plesetan yang tidak memiliki keterpaduan makna dan plesetan dengan permainan tipografi. Contoh plesetan yang tidak mempunyai keterpaduan makna seperti "Tujuh belas Agustus tahun empat lima, itulah hari....hari teh Sosro". Contoh plesetan permainan tipografi seperti "I am going' = ayam goreng, Takashimura $=$ Tak kasih murah; (2) Plesetan yang menjegal suatu kemapanan atau kelaziman rangkaian pesan, tetapi diikuti dengan terbentuknya sebuah rangkaian pernyataan baru yang mempunyai tingkat keterpautan formal. Contoh plesetan ini seperti: "tong kosong berbunyi .....glondang", yang seharusnya berupa kata "nyaring". Frasa "glondang (bunyi tong yang jatuh) mempunyai kaitan dengan "nyaring"; dan (3) Plesetan Oposisi, yaitu plesetan yang memberikan nalar dan acuan yang secara konfrontatif, bertabrakan, memutarbalikkan apa yang sudah ada, atau sudah lazim atau baku dalam masyarakat. Sebagai contoh “Rumah Sangat Sederhana (RSS) menjadi Raosipun Sumuk Sanget (rasanya panas sekali) dan Kitab Undang-undang Hukum Pidana (KUHP) menjadi Kasih Uang Habis Perkara" (Ariel Heryanto, 1996:111-116).

Cak Cuk Surabaya menggunakan pola bahasa plesetan sebagai peletup humor. Humor dapat menyalurkan ketegangan batin yang menyangkut ketimpangan norma masyarakat yang dapat dikendurkan melalui tawa. Sebagai homo ludens manusia gemarbermain, humor dapat membebaskan diri manusia dari beban kecemasan, kebingungan, kekejaman, dan kesengsaraan.Sama halnya dengan kartun, kritikan-kritikan yang disampaikan secara jenaka tidak begitu dirasakan melecehkan atau mempermalukan.

\section{PARODI VISUAL CAK CUK SURABAYA}

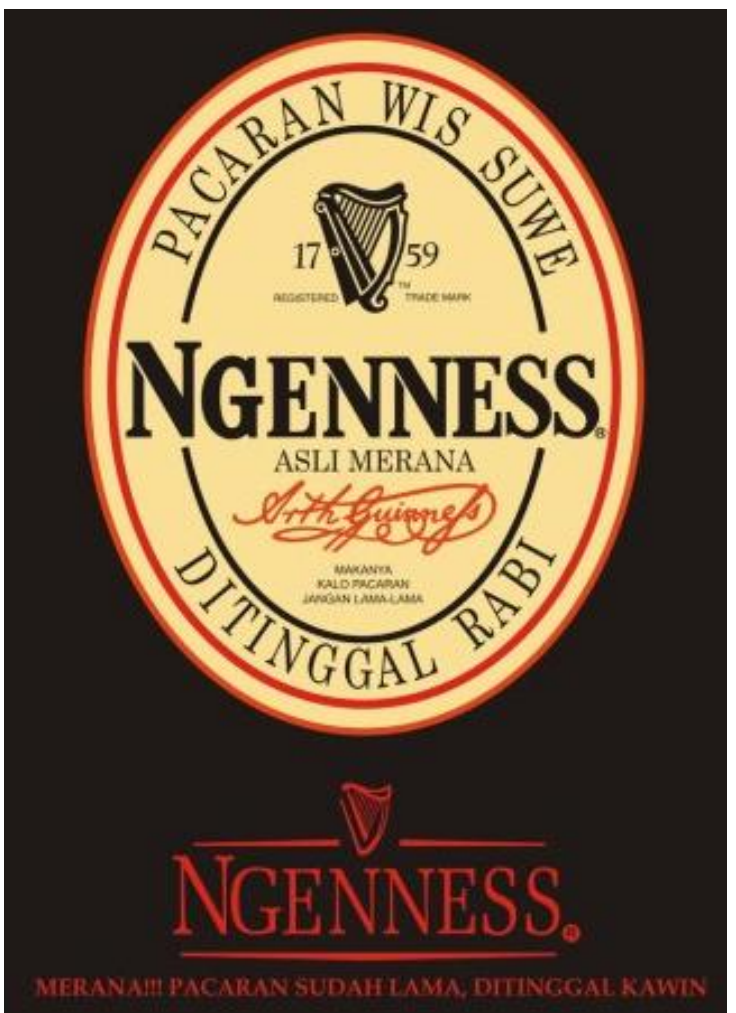

Gambar.7. Kaos Cak Cuk Surabayaparodi

Parodi merupakan salah satu bahasa visual yang sering digunakan sebagai medium humor dan penyampaian pesan. Menurut, Linda Hutcheon (dalam Sumbo Tinarbuko, 2007:6) mendefinisikan parodi sebagai suatu bentuk tiruan atau imitasi 
(visual) yang di dalamnya mengandung unsur-unsur ironi. Parodi merupakan sebuah relasi bentuk atau struktural antara dua teks.Sebuah teks baru dihasilkan dalam kaitan politisnya dengan teks rujukan yang bersifat serius.Parodi dalam posmodernisme merupakan sebuah wacana yang berupaya mempertanyakan kembali subjek pencipta sebagai sumber makna.

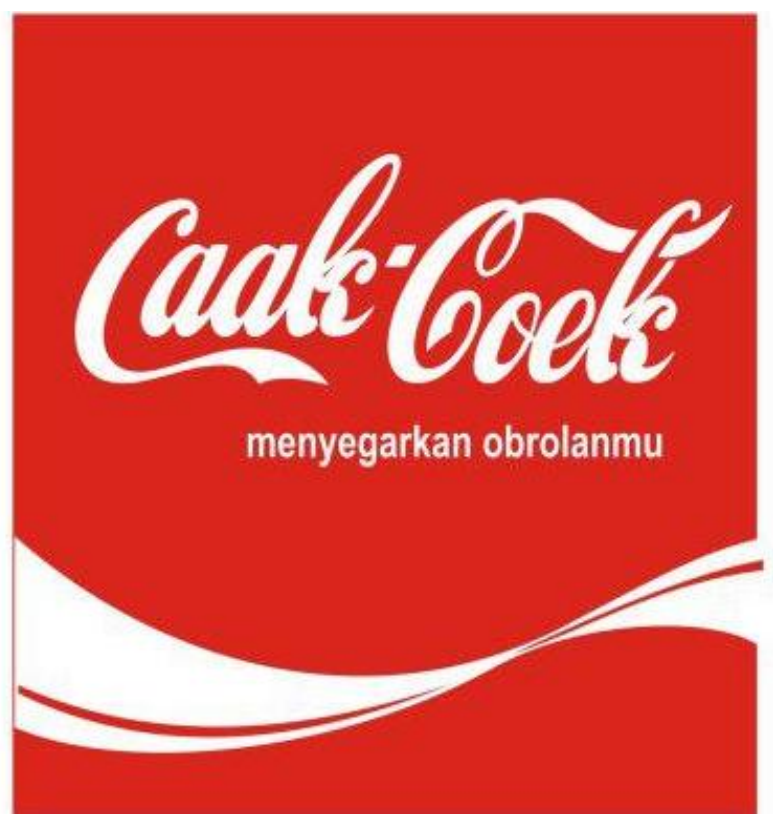

Gambar.8. Kaos Cak Cuk Surabayaparodi

Parodi menyiratkan satu upaya berdialog dengan masa lalu dan dengan sejarah.Ia membangun masa kini dengan merujuk pada seperangkat kode-kode sebagai satu upaya ideologis. Di dalam parodi terdapat sebuah ruang kritik, untuk mengungkapkan satu ketidakpuasan atau bisa juga sekadar ungkapan rasa humor belaka.Untuk itu, kritik, sindiran, kecaman, plesetan, olok-olok, main-main, seringkali dijadikan sebagai titik awal dari sebuah parodi.Karena itulah, sebagai salah satu strategi visual, parodi merupakan relasi visual dan makna di antara dua atau lebih teks atau gambar yang menghasilkan sebuah komposisi dan makna baru (Tinarbuko, 2007:6).Dalam pemahaman yang lain, Mikhail Bakhtin dalam bukunya berlabel The Dialogic Imagination seperti dikutip Piliang (1994:110) menyatakan parodi sebagai suatu bentuk representasi yang lebih menonjolkan aspek distorsi dan plesetan makna.

\section{LOKALITAS DALAM PARODI DAN PLESETAN KAOS CAK CUK SURABAYA}

Persoalan identitas memang menjadi persoalan penting dalam dunia yang semakin mengglobal ini. Di tengah percampuran bauran budaya yang semakin tumpang tindih, semangat lokalitas sepertinya menyeruakkan kembali kesadaran akan sebuah identitas. Tentu menjadi sebuah pertanyaan, seberapa pentingkah sebenarnya identitas itu di tengah dunia yang yang dipahami kaum Posmodernis penuh dengan realitas semu ini? Akan semakin rumit jawabannya kalau kita tambah lagi dengan pernyataan Shakespeare, “What is a name?' Memang, pada akhirnya semangat lokalitas tidak bisa dipisahkan dari identitas kultural. Ruang-ruang primordial yang terbentuk dari kesadaran akan kebersatuan kita dengan ruang lingkup sosial budaya tempat kita lahir dan dibesarkan. Keprimordialan ini pada akhirnya membuat kita menengok kembali pada tempat kita berpijak dan persoalanpersoalan keseharian kita yang selama ini agak terabaikan. Semangat lokalitas 
membuat kita sadar tempat kita berpijak (Adji,2011).

Perkembangan jaman telah mempermudah terjadinya komunikasi antar budaya.Dengan adanya teknologi informasi dan transportasi, sehingga memungkinkan terjadinya perbauran masyarakat dan budayanya dari berbagai latar belakang yang berbeda.Komunikasi antar budaya terjadi melalui berbagai perlintasan dan media, baik komunikasi tersebut dengan menggunakan kode-kode pesan secara verbal maupun nonverbal dalam interaksinya. Andrea L. Rich dan denis M. Ogawa menyatakan dalam buku Intercultural Communication, bahwa komunikasi antar budaya adalah komunikasi antara orang-orang yang berbeda kebudayaannya, misalnya antar suku bangsa, etnik, ras dan kelas sosial (dalam Liliweri 2003:12).

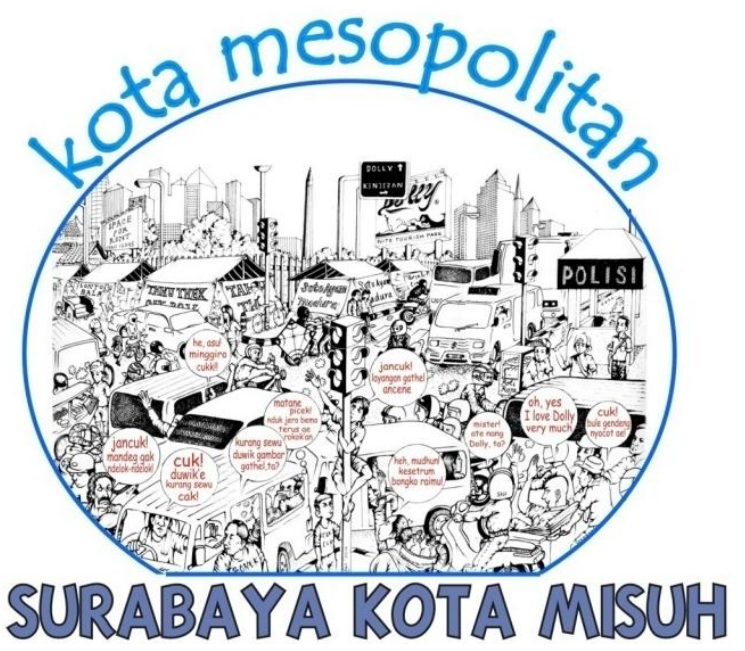

Gambar.9. Lokalitas Kaos Cak Cuk Surabaya

Bahasa plesetan dan parodi visual pada kaos Cak Cuk Surabaya meliputi beberapa fenomena pragmatik.Terkadang suatu plesetan berproses dari inspirasi terhadap sebuah merk dagang, fenomena sosial, peristiwa penting, tempat-tempat ikonik, atau pun tokoh-tokoh populer.Kaos Cak Cuk Surabaya membenturkan budaya populer dengan lokalitas yang nyuroboyo.Menggunakan bahasa suroboyoan, Cak Cuk Surabaya menghadirkan kembali humor lokal, bahkan tempat yang berkonotasi negatif namun sangat ikonik, lokalisasi Dolly.
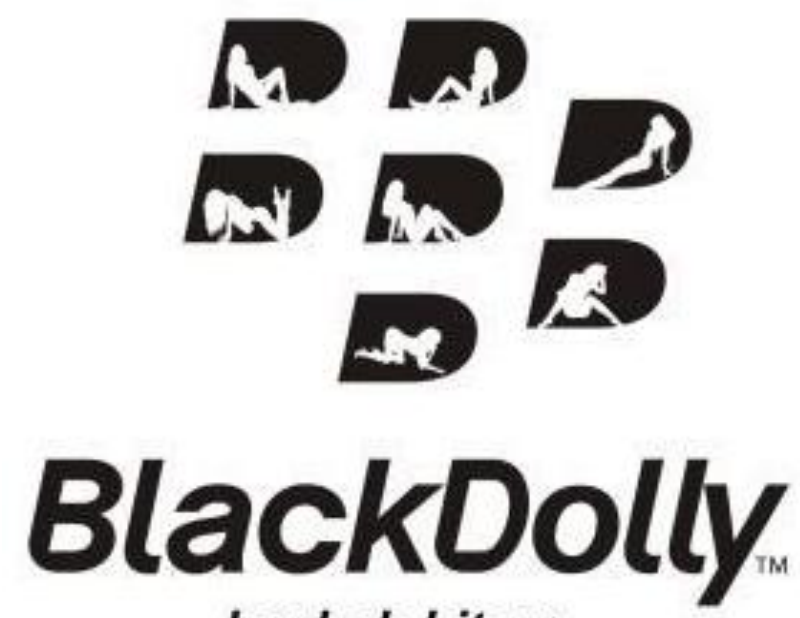
-lembah hitam-

Gambar.10. Lokalitas Kaos Cak Cuk Surabaya

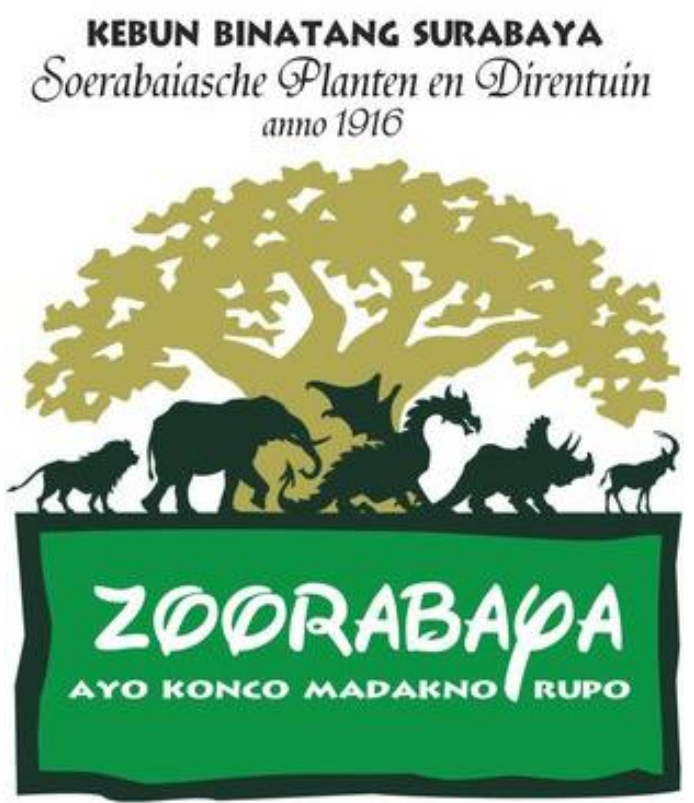

Gambar.11. Lokalitas Kaos Cak Cuk Surabaya 


\section{KESIMPULAN}

Kaos pada tataran dasarnya berfungsi sebagai penutup bagian tubuh dan daya tarik.Penggunaan bahasa plesetan dan parodi visual yang dipertemukan dengan lokalitas konten pada kaos Cak Cuk Surabaya merupakan fenomena yang menarik untuk dicermati dari aspek bahasa maupun visual.Dalam memahami tanda verbal maupun visual kaos Cak Cuk Surabaya kita tidak dapat mengabaikan konteks referensinya, yaitu lokalitas konten yang terkandung di dalam desain kaos Cak Cuk Surabaya.Cak Cuk berupaya menyindir tanpa menyakiti, mengkritik dengan jenaka, dan mencoba mempertahankan lokalitas suroboyoan di tengah desakan budaya luar yang semakin dalam penetrasinya.

\section{DAFTAR PUSTAKA}

1. Barnard, Malcolm. 2011. "Fashion Sebagai Komunikasi”, Yogyakarta : Jalasutra.

2. Heryanto, Ariel. 1996. "Pelecehan dan Kesewenang-wenangan Berbahasa Plesetan dalam Kajian Berbahasa dan Politik di Indonesia" dalam PELLBA 9: Linguistik Lapangan. Yogyakarta: Kanisius.

3. Liliweri, Alo. 2003 Makna Budaya dalam Komunikasi Antar Budaya", Yogjakarta : LkiS.

4. McRobbie, Angela, 1999, "In the Culture Society, Art, Fashion and Popular Music", London \& New York: Routledge.

5. Piliang, Yasraf A. 1994. Pastiche, Parodi, Kitsch, dan Camp. Jurnal Kalam. Edisi 2.

6. Tinarbuko, Sumbo. 2007. "Eksekusi Iklan Televisi dengan Pendekatan Parodi", dalam Jurnal Ilmu Komunikasi. Volume 4, nomor 1, juni 2007.

7. Wijana, Dewa Putu. 2003. "Kartun: Studi Tentang Permainan Bahasa" Yogyakarta: Ombak.

8. Suara Surabaya City Guide: edisi Mei 2012

9. Adji, Muhamad. "Lokalitas Dalam Karya Sastra Sebagai Upaya Pembentukan Identitas"PustakallmiahUnpad (http://pustaka.unpad.ac.id/wpcontent/uploads/20 11/03/lokalitas_dalam_karya_sastra.pdf)
10. http://kunci.or.id/

11. https://www.facebook.com/CakCukSurabayaAd minYangResmi 